\title{
Tratamiento de la faringitis aguda recurrente en niños
}

\section{Caso clínico}

Un niño de 9 años es llevado por sus padres al otorrinolaringólogo. Están muy preocupados porque el niño ha presentado en los últimos dos años varios episodios de faringitis aguda por estreptococo del grupo A. Los episodios fueron evaluados por el pediatra del niño y se resolvieron favorablemente con el tratamiento indicado (Penicilina $V$ o Amoxicilina).

El especialista les ofrece la cirugía como alternativa terapéutica.

\section{Pregunta que generó el caso}

En un niño con faringitis aguda a repetición (población) el tratamiento quirúrgico ¿es mejor que el tratamiento médico (intervención/comparación de tratamientos) para disminuir la incidencia de nuevos episodios de faringitis (resultado)?

\section{Búsqueda en Medline}

Se emplearon las siguientes palabras clave: "sore throat", "recurrent", y "tonsillectomy". La búsqueda fue específica para trabajos de terapéutica aleatorizados y controlados empleando e Clinical Queries que ofrece el PubMed. Se encontraron 2 traba jos: uno original (Paradise 1984) que comparó tratamiento quirúrgico vs. tratamiento médico, y una revisión sistemática que incluye en el análisis el citado trabajo original, entre otros. Por lo tanto sólo se comentará en este EOP's la revisión sistemática.

\section{Faringitis aguda recurrente (FAR) y Faringitis crónica (FC)}

El dolor de garganta es uno de los problemas más frecuentes por los que un niño es traído por sus padres a la consulta médica. Existen varias causas de faringitis aguda: bacterianas, virales e idiopáticas. En menos del $40 \%$ de los niños y del $10 \%$ de los adolescentes y adultos. Las faringitis agudas son producidas por el estreptococo del gupo A ( $S$. pyogenes).

La faringitis aguda recurrente puede definirse como 6 o más episodios de faringitis aguda en el último año. Sin embargo varios autores consideran que 3 o más episodios anuales en los últimos 3 años es una definición adecuada. La faringitis crónica requiere de una duracíon del episodio mayor de 3 meses.

La amigdalectomía es una de las cirugías más frecuentes realizadas en niños. La indicación más aceptada es la apnea obstructiva del sueño, en la cual la amigdalectomía se acompaña de adenoidectomía. Otras indicaciones más o menos aceptadas son la dificultad para tragar y la alteración de la fonación (voz nasal). No obstante, uno de los motivos más frecuentes para indicar la cirugía es la FAR y la FC. Su indicación en estos casos es controvertida y varía ampliamente.

\section{Resumen de la revisión sistemática encontrada}

Tonsillectomy versus non-surgical treatment for chronic/recurrent acute tonsillitis.

Burton MJ, Towler B, Glaziou P. In: The Cochrane Library,
Issue 2, 2000. Oxford: Update Software.

Este trabajo es una revisión sistemática realizada por la Colaboración Cochrane. Los autores consultaron diferentes bases de datos: Medline, Embase, y el Registro de Ensayos Controlados de la Cochrane. Como estrategia de búsqueda, emplearon el término TONSYL*; para identificar ensayos controlados de tratamiento quirúrgico versus tratamiento médico en la FAR y FC.

Los criterios de inclusión fueron los siguientes: a) tipo de estudio (ensayos controlados randomizados o no); b) tipo de participantes (adulto o niño con diagnóstico clínico (no se requería documentación microbiológica) con FAR o faringitis crónica (más de 3 meses); c) tipo de intervención: amigdalectomía vs cualquier otro tratamiento (antibióticos, analgesia, no tratamiento); d) tipo de resultado (primario: reducción del número y severidad de los episodios, y morbimortalidad de la cirugía; secundario: reducción en los días de ausentismo laboral o escolar). Los criterios de inclusión, así también como la calidad de los trabajos seleccionados, eran revisados en forma independiente por los 2 primeros autores. Cualquier diferencia de opinión era resuelta por el tercero de ellos. Se consultaron, además, las referencias de los trabajos encontrados y se contactó a los autores cuando era necesario.

\section{Resultados:}

No se identificaron estudios que evaluaran eficacia de la amigdalectomía en población adulta. Se encontraron 6 estudios en niños, 5 de los cuales fueron aleatorizados. Tres de estos últimos fueron excluídos debido a que la cirugía realizada incluía la adenoidectomía en una proporción no determinable y a que los criterios de inclusión eran poco estrictos (ej: la adenopatía cervical era considerada como criterio aislado de inclusión). De los 2 estudios restantes, ambos realizados en forma separada por Paradise (1984 y 1992), sólo el primero (1984) se halló disponible en forma completa, en tanto que los detalles del segundo (1992) se encontraron solamente en forma de abstract al momento de realizar esta revisión (1998). El estudio Paradise 1984 incluía niños severamente afectados de FAR (7 o más en el último año, o 5 al año en los últimos dos, o 3 por año en los últimos 3 años), de los cuales algunos fueron randomizados a grupo tratamiento quirúrgico o médico, mientras otros eran asignados según la preferencia de los padres (no incluídos en el análisis de esta revisión). Dentro del grupo quirúrgico algunos niños eran sometidos a la adenoidectomía, además de la amigdalectomía. Los autores hallaron diferencias significativas en la medición del resultado principal (número y severidad de los episodios luego de la intervención) durante los 2 primeros años de seguimiento. en favor del grupo quirúrgico. El análisis del 3er año de seguimiento no halló diferencias significativas. También encontraron diferencias en los resultados secundarios (días con dolor de garganta, adenopatía cervical fuera de una consulta por dolor de garganta y ausentismo escolar asociado a dolor de garganta), pero sólo durante el 1er. año de los tres en los que se realizó el seguimiento. Por otro lado, es importante destacar, como bien señalan los autores del Paradise, que aún los niños asignados al grupo no quirúrgico presentaron pocos episodios de faringitis, la mayoría de ellos leves, en los tres años de seguimiento. A pesar del intento de los autores de conducir el estudio en forma rigurosa -en una situación donde la intervención es imposible que sea ciega- es posible identificar sesgos que ponen en duda los resultados encontrados. Por un lado, el análisis de las poblaciones reveló importantes diferencias de base: el grupo quirúrgico incluía niños con más episodios en el último año (más afectados) que el grupo no quirúrgico. A su vez, los padres de los niños incluídos en este último grupo tenían un status socio-económico más alto que los del grupo quirúrgico. Por otro lado, el grupo quirúrgico incluía a niños con amigdalectomía con y sin adenoidectomía. Una parte importante del efecto de la cirugía podría deberse a la remoción de las adenoides. En relación al segundo estudio Paradise (1992) los autores 
señalan que es imposible con los datos disponibles evaluar objetivamente la eficacia de la intervención, y que esperan más información que incluirán en la actualización de esta revisión.

\section{Conclusión:}

Los autores de la revisión concluyen que no es posible determinar la eficacia de la amigdalectomía en la FAR o la FC debido a la insuficiente calidad metodológica de los estudios en los cuales ha sido evaluada.

\section{Comentario y Conclusión}

El dolor de garganta es uno de los problemas más frecuentes por los que un niño es traído por sus padres a la consulta. Como ya se ha dicho, menos del $40 \%$ de los niños y $10 \%$ de los adolescentes y adultos con faringitis aguda son positivas para el estreptococo del gupo A (S. pyogenes). La impresión clínica no es útil para discriminar la etiología. Se ha intentado desarrollar una regla de predicción clínica como herramienta para identificar con mayor exactitud los casos de faringitis estreptocóccica: la presencia de fiebre, exudado amigdalino, y adenomegalia cervical anterior dolorosa, y la ausencia de tos resulta en una probabilidad de entre 25 y $60 \%$ (según sea la prevalencia local de estreptococo) de que una faringitis sea producida por esta bacteria1. En estos casos (probabilidad pretest intermedia) es apropiado el empleo de un test diagnóstico, ya sea el cultivo (test de referencia) o la detección rápida de antígenos específicos de una muestra de hisopado de fauces, para lograr una mayor exactitud diagnóstica (probabilidad postest).

En relación a la FAR y FC por estreptococo varias hipótesis han sido propuestas para explicar su causalidad: 1) mala adherencia al tratamiento; 2) exposición repetida al estreptococo del grupo A (frecuentemente un portador en la familia); 3) eliminación de la flora comensal protectora por el empleo de la antibioticoterapia previa; 4) cepas resistentes; 5) copatógenos productores de betalacatamasa; 6) faringitis de otra causa en paciente portador del estreptococo del grupo A. Cuando se sospecha mala adherencia al tratamiento la penicilina benzatínica es una opción apropiada. Algunas estrategias terapéuticas sugeridas incluyen el uso de antibióticos de otras familias: macrólidos (en especial la azitromicina, por la ventaja de un régimen de monodosis por 5 días), clindamicina (aconsejada en casos especiales y no de rutina por el riesgo de colitis seudomembranosa), rifampicina (empleada siempre en combinación con otro agente debido a la rápida emergencia de resistencia cuando se emplea como monoterapia), o cefalosporinas (cefalexina, cefadroxilo, axetil-cefurixima)1,2. La amigdalectomía ha sido recomendada por algunos expertos en caso de que el niño persista con más de 607 episodios anuales de FAR a pesar del tratamiento apropiado?2.

La revisión sistemática realizada por Burton et al. Concluye que los estudios disponibles presentan sesgos metodológicos que no permiten evaluar apropiadamente la eficacia de la amigdalectomía en la FAR y FC.

El objetivo de este trabajo no fue evaluar la eficacia de la cirugía en la apnea obstructiva del sueño, indicación generalmente aceptada.

Sea cual fuere la indicación, es mandatorio informar a los padres acerca de los riesgos de la cirugía que, aunque poco frecuentes, pueden ser potencialmente fatales (riesgo anestésico, hemorragia postoperatoria)

Por el momento pareciera prudente esperar estudios de mejor calidad, que definan con precisión a la población estudiada, en cuanto a severidad de la afección y presencia de síntomas obstructivos, y el tipo de intervención (amigdalectomía con o sin adenoidectomía) para aclarar cúal es el rol de la cirugía en la FAR y $F C$

De igual importancia sería realizar un analisis de los beneficios de la intervención con relación a los riesgos de la misma, teniendo en cuenta que se trata de una afección con poca morbimortalidad, y cuya historia natural pareciera tender a la resolución espontánea.

\section{Dr. Sergio Dominelli [ Unidad de Medicina Familiar y Preventiva. Hospital Italiano de Buenos Aires ]}

\section{Referencias}

1 - Mclsaac WJ, White D, Tannenbaum D, Low D: A clinical score to reduce unnecessary antibiotic use in patients with sore throat, Can Med Assoc J, 158(1), 75-83, 1998 2 - Holm $S$ et al. Is penicillin the appropriate treatment for recurrente tonsyllopharyngitis? Rsults from a comparative randomized blind study of cefuroxime axetil and penicillin $V$ in children. The Swedish Study Group. Scand J Infect Dis 1995, 27(3):221-8 (Sólo Abstract disponible).

3 - Pichichero M, Sore Throat after sore throat after sore throat. Are you asking the critical question? Postgraduate Medicine 1997, 101(1):201-225.
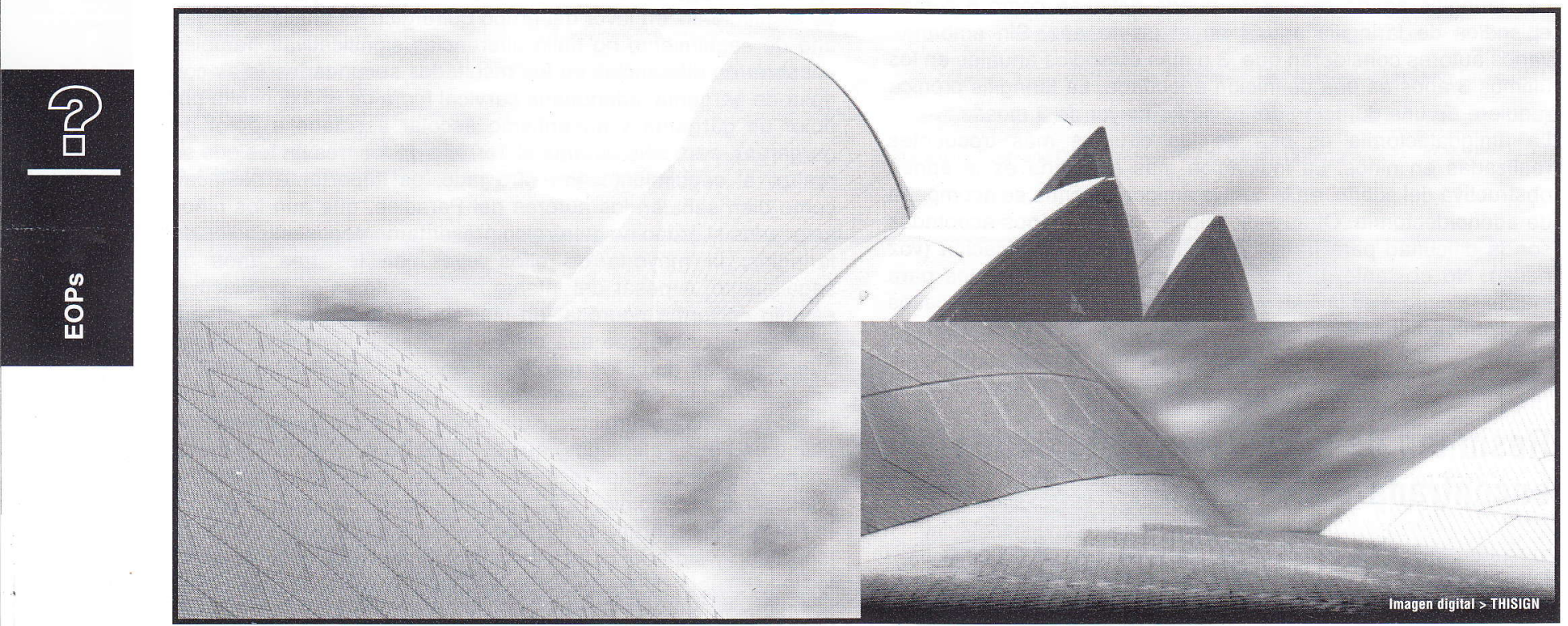